\title{
Gender differences on the WAIS-IV in patients with schizophrenia
}

\author{
Juan Carlos Ruiz, Inmaculada Fuentes, 2,3 Carmen Dasi, 'Marisa Navarro'
}

Departamento de Metodología de las Ciencias del Comportamiento Facultad de Psicología, Universidad de Valencia, Valencia, España.

2 Departamento de Personalidad, Evaluación y Tratamientos Psicológícos, Facultad de Psicología, Universidad de Valencia, Valencia, España. ${ }^{3}$ CIBERSAM, España.

Correspondence:

Juan Carlos Ruiz

Departamento de Metodología de las CC. del Comportamiento, Facultad de Psicología.

Avenida Blasco lbañez, 21

46010-Valencia, España.

Email: jeruiz@uv.es

Received: 17 January 2020

Accepted: 20 July 2020

Citation:

Ruiz, J. C., Fuentes, I., Dasi, C., \& Navarro, M. (2021). Gender differences on the WAIS-IV in patients with schizophrenia. Salud Mental, 44(1), 17-23.

DOI: $10.17711 /$ SM. $0185-3325.2021 .004$

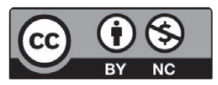

\begin{abstract}
Introduction. Results from studies that have investigated gender differences in neuropsychological functioning in schizophrenia have been inconsistent. Differences in the illness stage, in the demographic and clinical characteristics of the samples, and the instruments used to measure cognition may have contributed to the heterogeneity in the results. Objective. Investigate the heterogeneity in the results comparing cognitive functioning in chronically ill male and female patients with schizophrenia. Method. Twenty-five women and twenty-five men chronically ill patients with schizophrenia matched on age, age at illness onset, and years of education were evaluated in cognitive functioning using the WAIS-IV. Results. Men showed higher scores than women on the two global measures, on the perceptual reasoning and working memory indices, and on the information, visual puzzles, digit span, and arithmetic subtests of the WAIS-IV. Cohen's $d$ effect sizes were high for the two global measures and the two indices $(d>.68)$. Discussion and conclusion. Overall, in chronically stable patients with diagnosis of schizophrenia, women's performance on cognitive functioning was below men's when assessed with the WAIS-IV, except in the case of processing speed. This pattern of gender differences is similar to the pattern observed in healthy populations. Our results can help to clarify the heterogeneity in the results from studies on gender differences in cognitive functioning in schizophrenia and may be valuable in designing cognitive-targeted interventions for schizophrenia.
\end{abstract}

Keywords: Cognition, intelligence, confounding factors, schizophrenia, gender differences, WAIS-IV.

\section{RESUMEN}

Introducción. Los resultados de los estudios que han investigado diferencias de género en funcionamiento neuropsicológico en la esquizofrenia han sido inconsistentes. Diferencias en la fase de la enfermedad, en las características demográficas y clínicas de las muestras y en los instrumentos utilizados podrían explicar esa heterogeneidad. Objetivo. Investigar la heterogeneidad en los resultados comparando el funcionamiento cognitivo de pacientes con diagnostico de esquizofrenia. Método. Veinticinco mujeres y veinticinco hombres pacientes con diagnóstico de esquizofrenia equiparados en edad, edad al inicio de la enfermedad y nivel educativo se evaluaron en funcionamiento cognitivo utilizando la WAIS-IV. Resultados. Los hombres mostraron puntuaciones más altas que las mujeres en las dos medidas globales, en los índices de razonamiento perceptivo y de memoria de trabajo y en las subtests de la WAIS-IV de información, puzles visuales, amplitud de dígitos y aritmética. Los tamaños de efecto $d$ de Cohen fueron altos en las dos medidas globales y en los dos índices $(d>$.68). Discusión y conclusión. En conjunto, la ejecución de las mujeres en funcionamiento cognitivo está por debajo de la de los hombres cuando se mide con la WAIS-IV, excepto en el caso de la velocidad de procesamiento. Este patrón de diferencias de género es similar al patrón observado en población sana. Nuestros resultados pueden ayudar a clarificar la heterogeneidad de resultados en los estudios sobre diferencias de género en el funcionamiento cognitivo en la esquizofrenia y podrían ser útiles en el diseño de intervenciones centradas en la cognición.

Palabras clave: Cognición, inteligencia, factores confundentes, esquizofrenia, diferencias de género, WAIS-IV. 


\section{INTRODUCTION}

The review of the literature focused on the study of gender differences in cognitive performance in schizophrenia is a clear example of what Lewine, Haden, Caudle, and Shurett (1997) referred to as the salient problem in the study of schizophrenia: heterogeneity. Some reviews (Leger \& Neill, 2016; Leung \& Chue, 2000; Mendrek \& Mancini-Marïe, 2016; Ochoa, Usall, Cobo, Labad, \& Kulkarni, 2012), highlight that there is evidence of better cognitive performance in women than in men on attention, language, verbal memory, verbal learning, processing speed, and executive functioning, evidence of better cognitive performance in men than in women on working memory, attention/vigilance, and verbal memory (see also Bilder et al., 1992; Li et al., 2019; Rodriguez-Jimenez et al., 2015), and evidence of no differences. Moreover, these three types of results often appear within the same study.

Studies published since 2016 show a similar pattern of results, even when new methodological strategies have been introduced. In a large study with 544 community-dwelling patients with schizophrenia, Fond et al. (2018) found that men outperformed women on intellectual functioning, working memory, semantic memory, and non-verbal abstract thinking, and that women had better scores on processing speed and verbal learning. The results also showed the absence of gender differences in visuospatial learning abilities, cued verbal recall, sustained attention, and executive functioning. Li et al. (2019) studied gender differences by comparing the correlations between cognition and psychotic symptoms in women and men first-episode patients. The results were also heterogeneous: women and men showed similar correlations between negative symptoms and processing speed and working memory, but only men showed correlations between positive symptoms and shortterm and selective attention, why only women showed significant correlations between side effects from medication and working memory and processing speed.

Taken together, studies on gender differences in cognition in schizophrenia show that differences exist, although it is difficult to clearly delineate the profile of these differences. Methodological factors (Albus et al., 1997; Mendrek \& Mancini-Marie, 2016) have been pointed out as the reason for the heterogeneity and discrepancies in the results: sample size, clinical (onset age, medication, clinical symptoms, first-episode vs. chronic schizophrenia) and demographic (age, years of education) characteristics of patients, tests used to measure cognitive performance, sample selection bias with male patients being overrepresented, or the inclusion of control groups. To overcome these methodological concerns, one strategy has been to control demographic or clinical variables by matching groups of women and men (Fond et al., 2018; Goldstein et al., 1998; Hoff et al., 1998; Vaskinn et al., 2011), although this strategy may lead to non-representative sampling of the schizophrenic population as a whole (Leung \& Chue, 2000).

Our aim in the current study is to investigate gender differences in cognition in stable schizophrenia outpatients, using the Wechsler Adult Intelligence Scale - Fourth Edition (WAIS-IV), and matching the groups on potential confounding variables that have been hypothesized to moderate gender-based differences in cognitive performance in schizophrenia regardless of the neurological bases of these differences. Studies conducted since the 1990's on sex differences in brain anatomy of schizophrenia patients have shown that men have more severe morphological abnormalities than women (reduced frontal and temporal volumes; larger ventricular-brain ratio), revealing differences in the direction of normal sexual dimorphism (Mendrek et al., 2016). This morphological sexual dimorphism in schizophrenia extends to corticolimbic regions such as amygdala, hippocampus, hypothalamus and the orbitofrontal, anterior cingulate and insular cortex. More recent studies have evidenced also that female brains are more asymmetric than male brains in schizophrenia (Savadjiev et al., 2014). Since these brain structures are involved in cognitive functioning, it is reasonable to expect in schizophrenia patients gender differences in their patterns of cognitive deficits. However the delimitation of these patterns has proven to be complex. This fact adds a problem when designing cognitive rehabilitation therapies if the goal is to tailor them to the specific needs of a patient.

The WAIS-IV provides an intellectual performance score from 10 subtests that measure ten cognitive areas grouped in four global cognitive domains (verbal comprehension, perceptual reasoning, working memory, and processing speed). Studies in healthy populations have shown a consistent pattern of results when men and women have been compared using the different editions of the WAIS (studies with the WAIS-R: Lynn, 1998; van der Sluis et al., 2006; studies with the WAIS-III and WAIS-IV: Daseking, Petermann, \& Waldmann, 2017). Men performed better than women on the Full Scale Intelligence Quotient (FSIQ), the general ability index (GAI), verbal comprehension, perceptual reasoning, and working memory indices, and on the block design, matrix reasoning, arithmetic, visual puzzles, and information subtests. However, women performed better than men on the processing speed index and on the digit symbol and coding subtest.

To our knowledge, this is the first time that the full scale of the WAIS-IV has been used in a study on gender differences in cognition in patients with schizophrenia. This will allow to continue the work done in previous studies with earlier versions of the scale (WAIS-R and WAIS-III) or only with some of its subtests (Ayesa-Arriola et al., 2014; Bozikas et al., 2010; Fond et al., 2018; Goldstein et al., 1998; Lewine et al., 1997; Li et al., 2019; 
Longenecker, Dickinson, Weinberger, \& Elvevåg, 2010; Seidman et al., 1997; Torniainen et al., 2011; Zanelli et al., 2013). Moreover, in our study, a sample of women and a sample of men with the same size will be matched on age, years of education, and age at illness onset. Although this methodological option will not provide representative population samples of women or men patients with schizophrenia, we think it can contribute to providing data that can help to clarify cognitive gender differences in patients with schizophrenia. The unambiguous delineation of gender differences in cognition will facilitate the design of cognitive treatments tailored specifically to women and men in line, for example, with programs like the Integrated Neurocognitive Therapy (INT) (Roder \& Mueller, 2015) for schizophrenia patients. The INT has four modules that comprise different neuro and social cognitive remediation treatment areas with increasing complexity. Participation in the different modules could be decided attending the gender of the patient due to the their specific cognitive deficits.

In summary, our goal is to explore gender differences in the WAIS-IV in schizophrenia patients controlling some of the variables that have been hypothesized to explain the inconsistent results in the literature on gender differences in cognitive functioning in schizophrenia.

\section{METHOD}

\section{Subjects}

All the patients participated in a large project to compare the WAIS-IV profile of 99 patients to that of 99 demographically comparable healthy controls who participated in the WAIS-IV standardization and normative study of the Spanish version of the scale (Fuentes-Durá et al., 2019). The present study was carried out with the 25 females who participated in that study and a sample of 25 males matched with the female sample on age and years of education, and age at illness onset. All the participants lived in a urban area and were stable outpatients who had been diagnosed with schizophrenia according to DSMIV-TR criteria, using the Structured Clinical Interview for DSM-IV-TR Axis I Disorders (SCID-I) (First, Spitzer, Gibbon, \& Williams, 2002). Exclusion criteria were: previous traumatic brain injury, current substance abuse (in the previous year), and a FSIQ $<70$ on the WAIS-IV to avoid comorbidity with intellectual disability. All the patients were on stable doses of anti-psychotic medication, and severity of psychiatric symptoms was assessed using the Brief Psychiatric Rating Scale (BPRS) (Ventura, Green, Shaner, \& Liberman, 1993). Patients were active participants in rehabilitation programs in four outpatient psychiatric facilities.

\section{Measurements}

Wechsler Adult Intelligence Scale (WAIS-IV)

The scale includes 10 core subtests grouped in four indices: similarities, vocabulary, and information (Verbal Comprehension Index -VCI-); block design, matrix reasoning, and visual puzzles (Perceptual Reasoning Index -PRI-); digit span and arithmetic (Working Memory Index -WMI-); and symbol search and coding (Processing Speed Index -PSI-). All the subtests are used to obtain the FSIQ (Full Scale Intelligence Quotient), and the other global score, the GAI (General Ability Index), is derived from the subtests included in the VCI and the PRI. The four index scores, the FSIQ score, and the GAI score are standardized to a mean of 100 and a standard deviation of 15 .

\section{Procedure}

Our study was a descriptive cross-sectional study with the aim of comparing two groups, women and men, on cognitive functioning using a non-probabilistic sampling.

A trained clinical psychologist conducted the assessment in two sessions. Before the first sesión, relevant demographic and clinical data were collected based on the review of patient's clinical history. During the session, participants were informed about the study, and informed consent was obtained from all of them. In the second session, participants completed the ten core subtests of the WAIS-IV according to the standardized procedures outlined in the manual (Wechsler, 2012).

\section{Statistical analysis}

Differences between women and men in demographic and clinical characteristics were assessed using $t$-tests.

Scaled scores for each of the 10 core subtests of the WAIS-IV were generated for each participant and used to derive the four index scores and the FSIQ and GAI composite scores. The data were examined for normal distribution (skewness, kurtosis, and outlier analysis) and variance homogeneity. Differences between women and men participants on all these measures were explored using a multivariate analysis of variance (MANOVA). Furthermore, post hoc univariate analyses of variance (ANOVAs) were then performed to identify differences between women and men on each measure. To examine the magnitude of the differences between the two genders on all the subtests, indices, and general intelligence measures, effect sizes (Cohen's $d$ ) and confidence intervals for the effect sizes were calculated. Statistical analyses were performed with SPSS (IBM SPSS Statistics v. 24).

\section{Ethical considerations}

The study was conducted in accordance with the Code of Good Practices of the University of Valencia and the Hel- 
Table 1

Demographic and clinical characteristics of the study sample and group differences on the WAIS-IV Subtests, Index, FSIQ and GAI scores.

\begin{tabular}{|c|c|c|c|c|c|c|c|}
\hline & \multicolumn{2}{|c|}{$\begin{array}{l}\text { Women } \\
(N=25)\end{array}$} & \multicolumn{2}{|c|}{$\begin{array}{c}\text { Men } \\
(N=25)\end{array}$} & \multirow[b]{2}{*}{$t$} & \multirow[b]{2}{*}{$p$ value } & \\
\hline & $M$ & $S D$ & $M$ & $S D$ & & & \\
\hline Age in years & 48.04 & 9.03 & 45.80 & 8.12 & .92 & .361 & \\
\hline Age at onset of illness & 21.84 & 7.07 & 24.55 & 7.47 & 1.16 & .253 & \\
\hline Duration of illness in years & 26.05 & 11.61 & 21.30 & 11.81 & 1.27 & .213 & \\
\hline Years of education & 12.44 & 3.18 & 12.56 & 3.28 & .13 & .896 & \\
\hline BPRS score & 17.33 & 10.04 & 20.87 & 9.38 & 1.04 & .308 & \\
\hline \multicolumn{8}{|l|}{ Antipsychotic treatment (\%) } \\
\hline First generation & $11.11 \%$ & & $6.67 \%$ & & & & \\
\hline Second generation & $44.44 \%$ & & $80 \%$ & & & & \\
\hline First and second generation & $44.44 \%$ & & $13.33 \%$ & & & & \\
\hline \multirow[t]{2}{*}{$\underline{\text { Antipsychotic dosage }(\mathrm{mg})^{\mathrm{a}}}$} & 40.65 & 40.87 & 19.91 & 11.39 & 1.95 & .060 & \\
\hline & $M$ & $S D$ & $M$ & $S D$ & $F$ & $p$ value & $d$ \\
\hline Verbal Comprehension Index & 97.68 & 11.41 & 105.96 & 17.61 & 3.89 & .054 & .56 \\
\hline Similarities & 9.16 & 2.56 & 10.56 & 3.38 & 2.73 & .105 & .47 \\
\hline Vocabulary & 10.72 & 2.76 & 11.64 & 3.86 & 0.94 & .337 & .27 \\
\hline Information & 8.92 & 2.08 & 10.84 & 3.13 & 6.52 & .014 & .72 \\
\hline Perceptual Reasoning Index & 83.24 & 11.72 & 93.80 & 18.38 & 5.87 & .019 & .69 \\
\hline Block Design & 7.68 & 2.88 & 9.36 & 3.21 & 3.79 & .058 & .55 \\
\hline Matrix Reasoning & 7.36 & 2.78 & 8.48 & 3.31 & 1.68 & .201 & .37 \\
\hline Visual Puzzles & 7.12 & 2.35 & 9.24 & 3.62 & 6.03 & .018 & .69 \\
\hline Working Memory Index & 82.96 & 11.16 & 94.56 & 15.01 & 9.62 & .003 & .88 \\
\hline Digit Span & 7.72 & 2.53 & 9.40 & 3.27 & 4.14 & .047 & .58 \\
\hline Arithmetic & 6.64 & 2.06 & 8.92 & 3.21 & 8.92 & .004 & .84 \\
\hline Processing Speed Index & 81.08 & 11.56 & 83.84 & 17.45 & .44 & .513 & .19 \\
\hline Symbol Search & 6.52 & 2.35 & 7.44 & 3.43 & 1.23 & .274 & .31 \\
\hline Coding & 6.60 & 2.42 & 6.64 & 3.23 & .01 & .961 & .01 \\
\hline Full Scale IQ & 83.16 & 10.50 & 94.96 & 15.79 & 9.68 & .003 & .88 \\
\hline General Ability & 89.00 & 11.03 & 100.00 & 16.99 & 7.37 & .009 & .77 \\
\hline
\end{tabular}

Note: BPRS: Brief Psychiatric Rating Scale. Wilks Lambda in the MANOVA: $\Lambda=.46 ; p=.016 ; d$ : Cohen's d effect size.

a In Olanzapine equivalents (Leucht, Samara, Heres, \& Davis, 2016).

sinki Declaration. Written informed consent was obtained from all participants prior to their inclusion in the study and all data were collected in an anonymous database.

\section{RESULTS}

Demographic and clinical characteristics of the two samples, women and men patients, are described in Table 1. The two groups did not differ on age, age at illness onset, illness duration, years of education, symptomatology, or antipsychotic dosage.

Mean subtest, index, FSIQ, and GAI scores are presented in Table 1. The MANOVA analysis of the scores on the ten WAIS-IV subtests, the four cognitive indices, and the GAI and FSIQ showed a main effect of gender [F $(16,33)$ $=2.41, p=.016, \Lambda=.46]$. Post hoc univariate ANOVAs revealed significant differences between the women's group and the men's group on the information, visual puzzles, digit span, and arithmetic subtests, and differences that approached significance on the block design subtest $(p=.058)$ (Figure 1). On all these subtests, men had higher scores than women. Men also obtained higher scores than women on the Perceptual Reasoning and Working Memory Indices, and the difference between the two groups nearly reached significance on the Verbal Comprehension Index ( $p=.054)$. Men also performed better than women on the Full-Scale IQ and the General Ability Index (Figure 2).

Effect sizes (Table 1) for the similarities, information, block design, visual puzzles, digit span, and arithmetic subtests and the Verbal Comprehension, Perceptual Reasoning, and Working Memory Indices were in the medium range. The magnitude of the difference between the two samples on the FSIQ and GAI scores was large. However, the dif- 


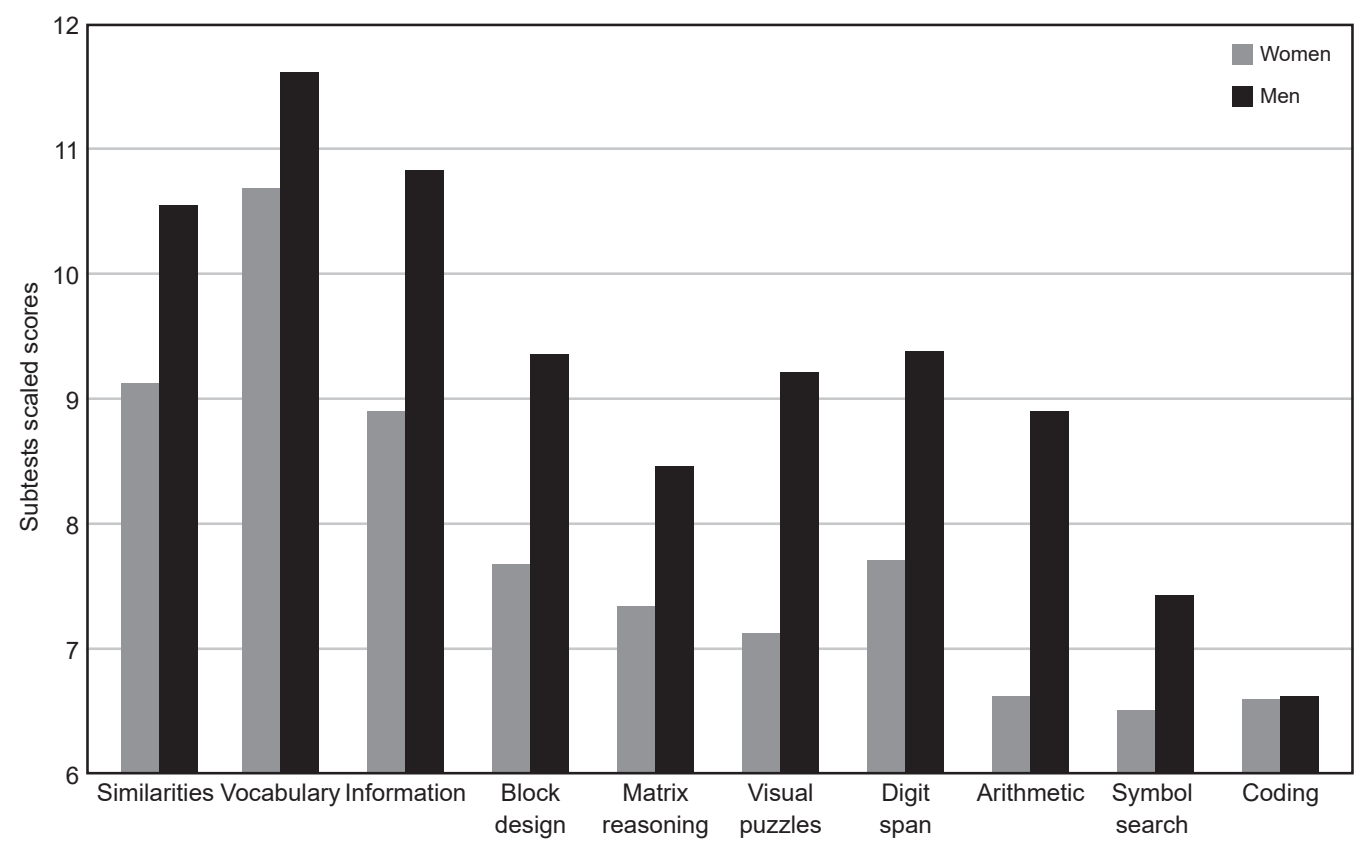

Figure 1. Performance of women and men on the WAIS-IV subtests.

ferences between women and men on the subtests, indices, and global scores that showed significant differences were equivalent. Confidence intervals for the effect sizes in these cases overlapped (Figure 3).

\section{DISCUSSION AND CONCLUSSION}

This study aimed to investigate gender differences in cognition in schizophrenia using the WAIS-IV. Men outperformed women on the two global intelligence measures

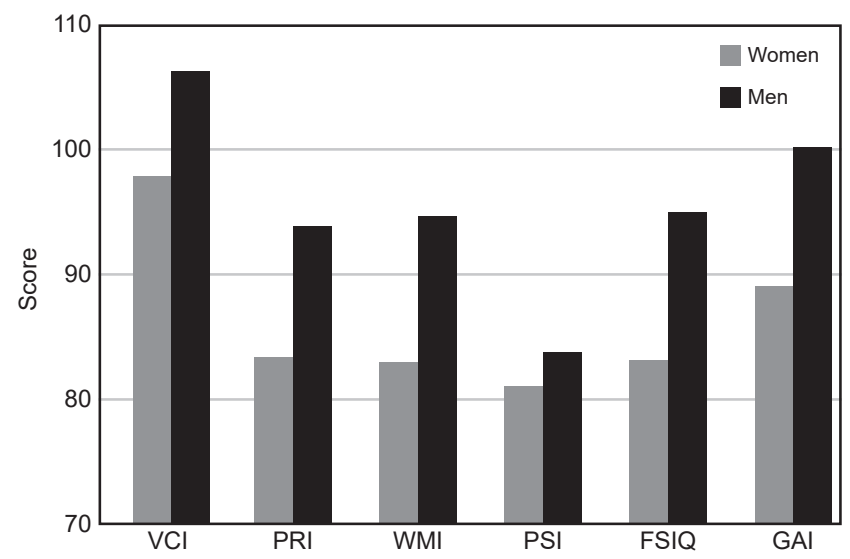

Figure 2. Performance of women and men on the indices and global intelligence measures of the WAIS-IV.

VCI: Verbal comprehension; PRI: Perceptual reasoning; WMI: Working memory; PSI: Processing speed; FSIQ: Full scale IQ; GAl: General ability index.
(FSIQ and GAI) and on two indices of the scale (WMI and PRI). The effect sizes of these differences were above .68 . Differences on the VCI were near significance. Differences were also significant on the subscales of information, visual puzzles, digit span, and arithmetic, and near significance on block design. As on the indices, performance in men was better than in women. To our knowledge, this is the first study to use the complete latest version of the WAIS-IV to study gender differences in cognition in schizophrenia and, overall, the results show that women's performance on the WAIS-IV was below men's.

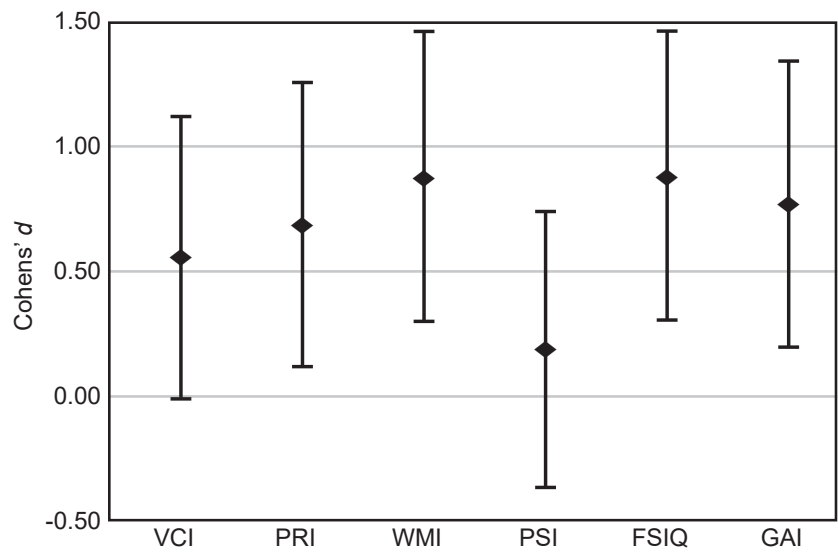

Figure 3. Effects sizes (Cohens' d) with Confidence Intervals on the indices and global intelligence measures of the WAIS-IV.

VCl: Verbal comprehension; PRI: Perceptual reasoning; WMI: Working memory; PSI: Processing speed; FSIQ: Full scale IQ; GAI: General ability index. 
Our results are consistent with previous studies in similar schizophrenia populations using earlier versions of the WAIS that found better scores for men than for women on full scale IQ, working memory index, verbal IQ, and performance IQ (Fond et al., 2018; Lewine et al., 1997). As in our study, in these two studies women and men were matched on the variable years of education. In contrast to studies reporting less cognitive impairment in women, it seems that equating women and men education level, age, and age at onset evidence a different pattern of results. In their study Longenecker et al. (2010) measured verbal memory and processing speed using the WMS-R and the WAIS-R and found better performance in women than in men, but the groups were not equated in any of the variables age, education level, or age at onset. Bozikas et al. (2010) used two subtests of the WMS-III to measure attention and working memory and did not found gender differences. In their study, women and men did not differ on age and age at onset but were different in education level. In the study of Goldstein et al. (1998), they used subtests of the WAIS-R along with other tests to measure different cognitive domains. In contrasts to our results male participants in the study performed below female patients on attention, language, verbal memory, and executive functions. The sample size of the study was small, 14 women and 17 men, and the groups were not equivalent in education level. Other studies in which gender differences have been assessed using different tests or cognitive batteries, but without the control of the education level, age or age at onset (Hoff et al., 1998), have not found gender differences.

Results in studies that have involved first-episodic patients (Albus et al., 1997; Ayesa-Arriola et al., 2014; Bilder et al., 1992; Hoff et al., 1998; Ittig et al., 2015; Li et al., 2019; Zanelli et al., 2013; Mesholam-Gately, Giuliano, Goff, Faraone, \& Seidman, 2009) consistently show a better performance by women on executive functioning, language, and verbal memory. Overall, our study does not replicate these results.

Our results do no support the general hypothesis that female patients show less cognitive impairment than males (Goldstein et al., 1998; Longenecker et al., 2010). The older age at onset of the illness in women probably allows them to complete a greater number of years of study or educational level, which could explain their observed better cognitive performance. Our data showed that when women and men patients are equated in education level, age, and age at illness onset, the pattern of results change a with better performance of men in most cognitive domains. We do not think that we have evidence an overall different cognitive pattern of results in women, but a different one in men because the study has equated men to women in these variables. The usual over representation of men in the studies, along with their lower education level due to a general earlier illness onset, could be the reason of the common re- sult in the literature of a worst cognitive performance than women.

When compared with results in healthy control groups, our results follow the pattern observed in control population studies with the WAIS-IV. Daseking et al. (2017) studied gender differences in cognitive abilities in the total national standardization sample of the WAIS-IV in Germany. Their results showed that women score lower than men on the FSIQ and GAI and on all indices and subtests, with the exception of the PSI and its subtests, on which women outperformed men. The results of our study fit those from this research for all the indices and subscales in which gender differences were significant or approached significance, including differences in the Full Scale IQ and General Ability Index. Overall, our results indicate that gender differences in cognitive performance in stable chronically ill patients with schizophrenia are not different from those observed in healthy controls when women and men patients have the same age, education level, age at illness onset, illness duration, and symptoms. Knowledge about these gender differences may be relevant in designing cognitive-targeted interventions in schizophrenia tailored to stable chronically ill patients.

This study has some limitations. First, the two groups have a small sample size, but they are in the range of sample sizes used in previous studies [e.g., 14 women and 17 men in Goldstein et al. (1998) and 23 women and 51 men in Hoff et al. (1998)]. Future studies with larger sample sizes could help to see slight differences between women and men not shown in our study. Second, the WAIS-IV was the only scale used to assess cognitive functioning. Although it is a widely used instrument to evaluate cognitive functioning in healthy populations, it does not evaluate all the cognitive domains. Finally, although the antipsychotic dosage was equivalent in the two groups, the type of antipsychotic can influence patients' cognitive functioning.

\section{Funding}

None.

\section{Conflict of interest}

The authors declare that they have no conflicts of interest.

\section{REFERENCES}

Albus, M., Hubmann, W., Mohr, F., Scherer, J., Sobizack, N., Franz, U., ... Wahlheim, C. (1997). Are there gender differences in neuropsychological performance in patients with first-episode schizophrenia? Schizophrenia Research, 28(1), 3950. doi: 10.1016/S0920-9964(97)00091-1

Ayesa-Arriola, R., Rodriguez-Sanchez, J. M., Gomez-Ruiz, E., Roiz-Santiáñez, R., Reeves, L. L., \& Crespo-Facorro, B. (2014). No sex differences in neuropsychological performance in first episode psychosis patients. Progress in Neuro-Psychopharmacology and Biological Psychiatry, 48, 149-154. doi: 10.1016/j.pnpbp.2013.09.009

Bilder, R. M., Lipschutz-Broch, L., Reiter, G., Geisler S. H., Mayerhoff, D. I., \& Lieberman, J. A. (1992). Intellectual deficits in first-episode schizophrenia: 
Evidence for progressive deterioration. Schizophrenia Bulletin, 18(3), 437-448. doi: 10.1093/schbul/18.3.437

Bozikas, V. P., Kosmidis, M. H., Peltekis, A., Giannakou, M., Nimatoudis, I., Karavatos, A., ... Garyfallos, G. (2010). Sex differences in neuropsychological functioning among schizophrenia patients. Australian and New Zealand Journal of Psychiatry, 44(4), 333-341. doi: 10.3109/00048670903489833

Daseking, M., Petermann, F., \& Waldmann, H.-C. (2017). Sex differences in cognitive abilities: Analyses for the German WAIS-IV. Personality and Individual Differences, 114, 145-150. doi: 10.1016/j.paid.2017.04.003

First, M. B., Spitzer, R. L., Gibbon, M., \& Williams, J. B. W. (2002). Structured Clinical Interview for DSM-IV-TR Axis I Disorders (SCID-I/P). New York: Biometrics Research, New York State Psychiatric Institute.

Fond, G., Boyer, L., Leboyer, M., Godin, O., Llorca, P. M., Andrianarisoa, M., ... Bulzacka, E. (2018). Influence of Venus and Mars in the cognitive sky of schizophrenia. Results from the first-step national FACE-SZ cohort. Schizophrenia Research, 195, 357-365. doi: 10.1016/j.schres.2017.09.027

Fuentes-Durá, I., Ruiz, J. C., Dasí, C., Navarro, M., Blasco, P., \& Tomás, P. (2019). WAIS-IV Performance in Patients with Schizophrenia. The Journal of Nervous and Mental Disease, 207(6), 467-473. doi: 10.1097/NMD.0000000000000997

Goldstein, J. M., Seidman, L. J., Goodman, J. M., Koren, D., Lee, H., Weintraub, S., \& Tsuang, M. T. (1998). Are there sex differences in neuropsychological functions among patients with schizophrenia? The American Journal of Psychiatry, 155(10), 1358-1364. doi: 10.1176/ajp.155.10.1358

Hoff, A. L., Wieneke, M., Faustman, W. O., Horon, R., Sakuma, M., Blankfeld, H., ... DeLisi, L. E. (1998). Sex differences in neuropsychological functioning of first-episode and chronically ill schizophrenic patients. The American Journal of Psychiatry, 155(10), 1437-1439. doi: 10.1176/ajp.155.10.1437

Ittig, S., Studerus, E., Papmeyer, M., Uttinger, M., Koranyi, S., Ramyead, A. \& Riecher-Rössler, A. (2015). Sex differences in cognitive functioning in at-risk mental state for psychosis, first episode psychosis and healthy controls subjects. European Psychiatry, 30(2), 242-250. doi: 10.1016/j.eurpsy.2014.11.006

Leger, M., \& Neill, J. C. (2016). A systematic review comparing sex differences in cognitive function in schizophrenia and in rodent models for schizophrenia, implications for improved therapeutic strategies. Neuroscience \& Biobehavioral Reviews, 68, 979-1000. doi: 10.1016/j.neubiorev.2016.06.029

Leucht, S., Samara, M., Heres, S., \& Davis, J. M. (2016). Dose Equivalents for Antipsychotic Drugs: The DDD Method. Schizophrenia. Bulleting, 42(Suppl 1), S90-S94. doi: 10.1093/schbul/sbv167

Leung, A. \& Chue, P. (2000). Sex differences in schizophrenia, a review of the literature. Acta Psychiatrica Scandinavica, 101(401), 3-38. doi: 10.1111/j.00651591.2000.0ap25.x

Lewine, R., Haden, C., Caudle, J., \& Shurett, R. (1997). Sex-onset effects on neuropsychological function in schizophrenia. Schizophrenia Bulletin, 23(1), 51-61. doi: 10.1093/schbul/23.1.51

Li, A. W. Y., Hui, C. L. M., Lee, E. H. M., Chang, W. C., Chan, S. K. W., \& Chen, E. Y. H. (2019). Gender differences in correlates of cognition in firstepisode psychosis. Psychiatry Research, 271, 412-420. doi: 10.1016/j. psychres.2018.12.011

Longenecker, J., Dickinson, D., Weinberger, D. R., \& Elvevåg, B. (2010). Cognitive differences between men and women: A comparison of patients with schizophrenia and healthy volunteers. Schizophrenia Research, 120(1-3), 234235. doi: 10.1016/j.schres.2009.12.009
Lynn, R. (1998). Sex differences in intelligence: Data from a Scottish standardisation of the WAIS-R. Personality and Individual Differences, 24(2), 289-290. doi: 10.1016/S0191-8869(97)00165-7

Mendrek, A., \& Mancini-Marïe, A. (2016). Sex/gender differences in the brain and cognition in schizophrenia. Neuroscience \& Biobehavioral Reviews, 67, 57-78. doi: 10.1016/j.neubiorev.2015.10.013

Mesholam-Gately, R. I., Giuliano, A. J., Goff, K. P., Faraone, S. V., \& Seidman, L. J. (2009). Neurocognition in first-episode schizophrenia: A meta-analytic review. Neuropsychology, 23(3), 315-336. doi: 10.1037/a0014708

Ochoa, S., Usall, J., Cobo, J., Labad, X., \& Kulkarni, J. (2012). Gender differences in schizophrenia and first-episode psychosis: A comprehensive literature review. Schizophrenia Research and Treatment, Article ID 916198, 1-9. doi: 10.1155/2012/916198

Roder, V., \& Müller, D. R. (2015). INT-Integrated Neurocognitive Therapy for Schizophrenia Patients. Springer International Publishing Switzerland.

Rodriguez-Jimenez, R., Dompablo, M., Bagney, A., Santabárbara, J., Aparicio, A. I., Torio, I., ... Palomo, T. (2015). The MCCB impairment profile in a Spanish sample of patients with schizophrenia: Effects of diagnosis, age, and gender on cognitive functioning. Schizophrenia Research, 169(1-3), 116-120. doi: 10.1016/j.schres.2015.09.013

Savadjiev, P., Whitford, T. J., Hough, M. E., Clemm von Hohenberg, C., Bouix, S., Westin, C.-F., ... Kubicki, M. (2014). Sexually dimorphic white matter geometry abnormalities in adolescent onset schizophrenia. Cerebral Cortex, 24(5), 13891396. doi: 10.1093/cercor/bhs422

Seidman, L. J., Goldstein, J. M., Goodman, J. M., Koren, D., Turner, W. M., Faraone, S. V., \& Tsuang, M. T. (1997). Sex differences in olfactory identification and Wisconsin card sorting performance in schizophrenia: Relationship to attention and verbal ability. Biological Psychiatry, 42(2), 104-115. doi: 10.1016/S00063223(96)00300-9

Torniainen, M., Suvisaari, J., Partonen, T., Castaneda, A. E., Kuha, A., Perälä, J., ... Tuulio-Henriksson, A. (2011). Sex differences in cognition among persons with schizophrenia and healthy first-degree relatives. Psychiatry Research, 188(1), 7-12. doi: 10.1016/j.psychres.2010.11.009

van der Sluis, S., Posthuma, D., Dolan, C. V., de Geus, E. J. C., Colom, R., \& Boomsma, D. I. (2006). Sex differences on the Dutch WAIS-III. Intelligence, 34(3), 273-289. doi: 10.1016/j.intell.2005.08.002

Vaskinn, A., Sundet, K., Simonsen, C., Hellvin, T., Melle, I., \& Andreasen, O. A. (2011). Sex differences in neuropsychological performance and social functioning in schizophrenia and bipolar disorder. Neuropsychology, 25(4), 499-510. doi: 10.1037/a0022677

Ventura, J., Green, M. F., Shaner, A., \& Liberman, R. P. (1993). Training and quality assurance with the Brief Psychiatric Rating Scale: "the drift busters". International Journal of Methods in Psychiatric Research, 3(4), 221-244.

Wechsler, D. (2012). Escala de Inteligencia de Wechsler para Adultos-Cuarta Edición: Manual técnico y de interpretación. Madrid: Pearson.

Zanelli, J., Morgan, K., Dazzan, P., Morgan, C., Russo, M., Pilecka, I., ... Reichenberg, A. (2013). Gender differences in neuropsychological performance across psychotic disorders-a multi-centre population basedcase-control study. PLoS ONE, 8(10), e 77318. doi: 10.1371/journal.pone.0077318 